\title{
MARMOUSI, MODEL AND DATA
}

\author{
Aline Bourgeois, Marielle Bourget, Patrick Lailly, \\ Michel Poulet, Patrice Ricarte and Roelof Versteeg \\ Institut Français du Pétrole \\ $1 \& 4$ av. de Bois-Préau BP 311 \\ 92506 Rueil-Malmaison \\ France
}

\begin{abstract}
In 1988 a complex 2D model was created and synthetic seismic data were generated from this model. Model and data were designed specifically by the IFP for the blind test of the Copenhagen workshop. This article describes the philosophy behind the model and the creation of model and data.
\end{abstract}

\section{The Model}

\section{Philosophy behind the model}

Before the creation of the model several demands were formulated to which the model (and the data) should adhere. First, the model should be geologically plausible, meaning that it preferably should be based on a real situation. Second, the model should be complex, meaning that it must contain many reflectors, steep dips and strong velocity gradients in both vertical and lateral directions. Thus, the data should be so complex that the assumptions on which conventional processing relies should not hold: obtaining a good image from the data should require the use of depth imaging methods like prestack depth migration or inversion. Obviously the creation of such a model requires the cooperation of geologists, geophysicists and computer scientists.

\section{Model generation}

The Marmousi model is based on a profile through the North Quenguela trough in the Cuanza basin (Angola) (fig. 1) as described in Verrier and Branco (1972).

Based on this section a geometric model containing 160 layers was created using the MIMIC ${ }^{\mathrm{TM}}$ module of the SIERRA package (colour figure 1). Then the velocity and density distributions were defined by introducing realistic horizontal and vertical velocity gradients. The velocity distribution in the shallower part of the series (the detrital series) has a high vertical gradient to model the strong compaction. This model was transformed into a 2-D velocity/density grid (colour figures 2 and 3) with dimensions 9200 meters (horizontal distance) by 3000 meters (depth) with a grid size of 4 meters (both horizontal and vertical).

\section{Geological model description}

The geological model of the basin consists of:

- A deltaic sediment interval, thickening from west to east, deposited upon a saliferous evaporitic series. In the eastern part, which seems to be more affected by the continuous lateral salt creep, normal growth faults are developed.

- presaliferous folded carbonate platform deposits, in which a structural hydrocarbon trap is expected. 


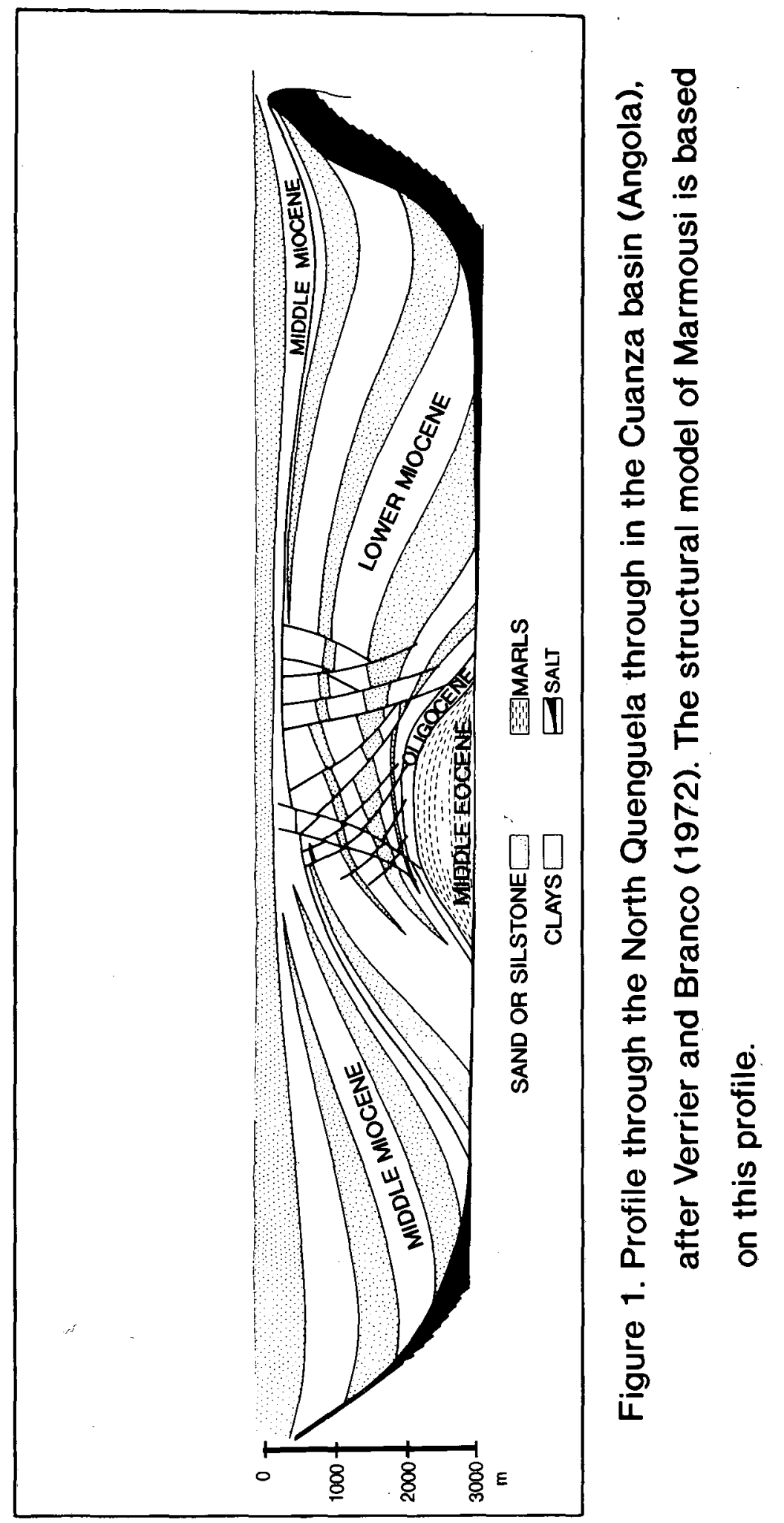




\section{Geological History}

The geological history consists of two quite distinct phases:

The first phase corresponds to a continuous platform sedimentation (of marls and carbonates). At the end of this sedimentation these deposits were slightly folded and then eroded (with the erosion surface being flat).

The second phase began with the deposition of an isopachous saliferous evaporitic series. On this series, a clayey-marly series rich in organic matter was deposited.

These sediments were followed by a thick deposit of shaly-sandy detrital sediments whose facies thickness was governed by continuous lateral creep of salt, resulting from the overburden pressure. Linked to this salt creep, which may locally cause complete disappearance of the salt, slanting growth faults appeared and were active continuously during the deposition of the detrital series.

\section{Petroleum Prospects}

In the detrital series, traps are formed by structures linked to the salt tectonics (residual salt cushion, inversion of depocenters as result of the departure of the salt) complicated by growth faults.

The hydrocarbon supply in the sands occurred per ascensum from the post-evaporitic source rock series.

In the lower antesaliferous series, there are vast anticlinal structures which, in the absence of salt (which disappeared by lateral creep) were supplied per descensum by the overlying source rock series.
The three wells for which data are available cross through an unfaulted sedimentary series in which the shaly-marly source rocks are absent.

\section{The seismic data}

\section{Acquisition}

The line was shot from west to east. The first and last shot points were respectively located at 3000 and 8975 meters from the west edge of the model. The distance between two consecutive shots was 25 meters.

The source consisted of 6 waterguns with a spread of 40 meters, the interval between guns being 8 meters. The shot point position was in the middle of the source array (figure 2) and source depth was 8 meters. All sources emitted the same wavelet and were "fired" at the same moment.

The watergun wavelet used for the modeling (figure 3) was obtained by digitizing a real near field signal which was filtered with a trapezoid frequency filter $(0,10,40,60 \mathrm{~Hz})$. Applying this filter has roughly the same effect as a band-pass filter applied during recording.

The streamer was composed of 96 hydrophone groups. The distance between two consecutive groups was 25 meters (figure 4). Initial offset was 200 meters; the maximum offset was thus 2575 meters.

Each hydrophone group consisted of 5 hydrophones with a distance between hydrophones of four meters. The trace for each group was obtained by a sum of the 5 hydrophone traces. The streamer depth was 12 meters.

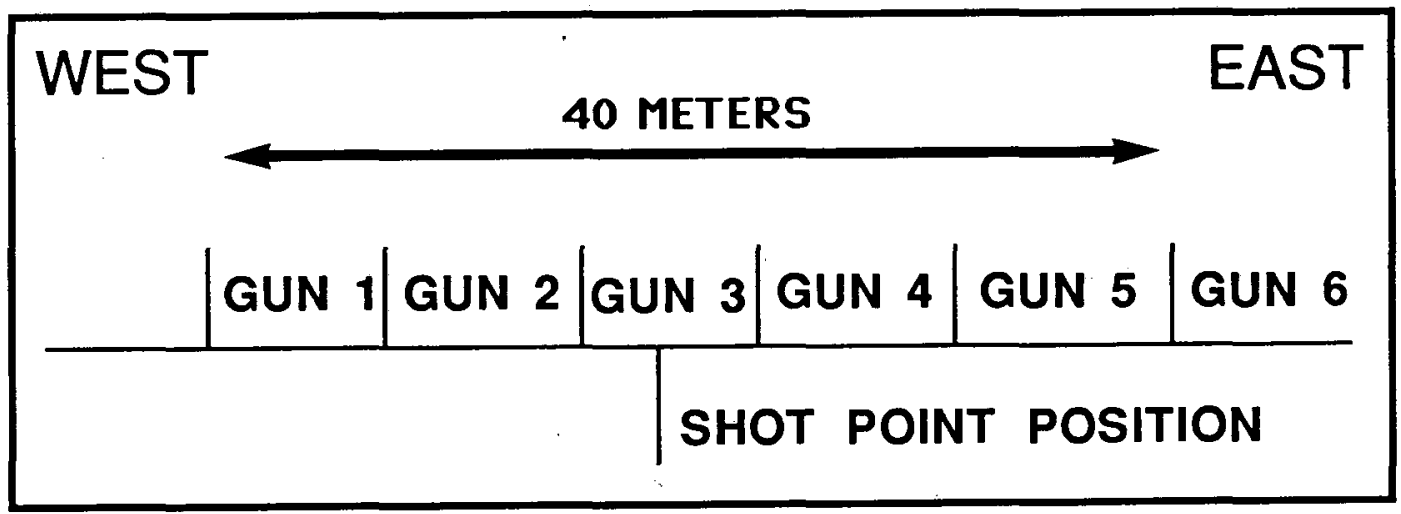

Figure 2. Source pattern used for the data generation. 


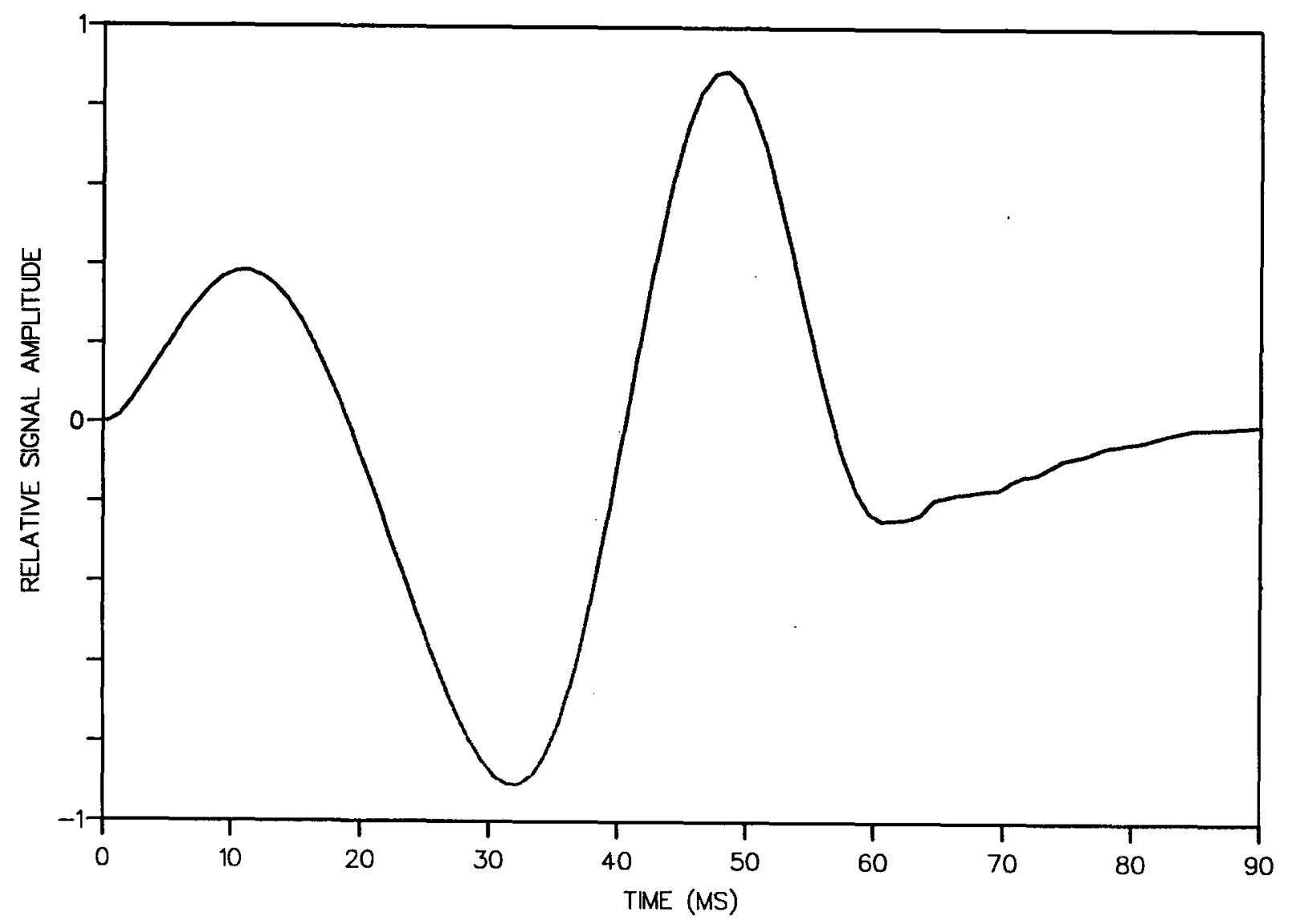

Figure 3. Source signal used for the data generation.

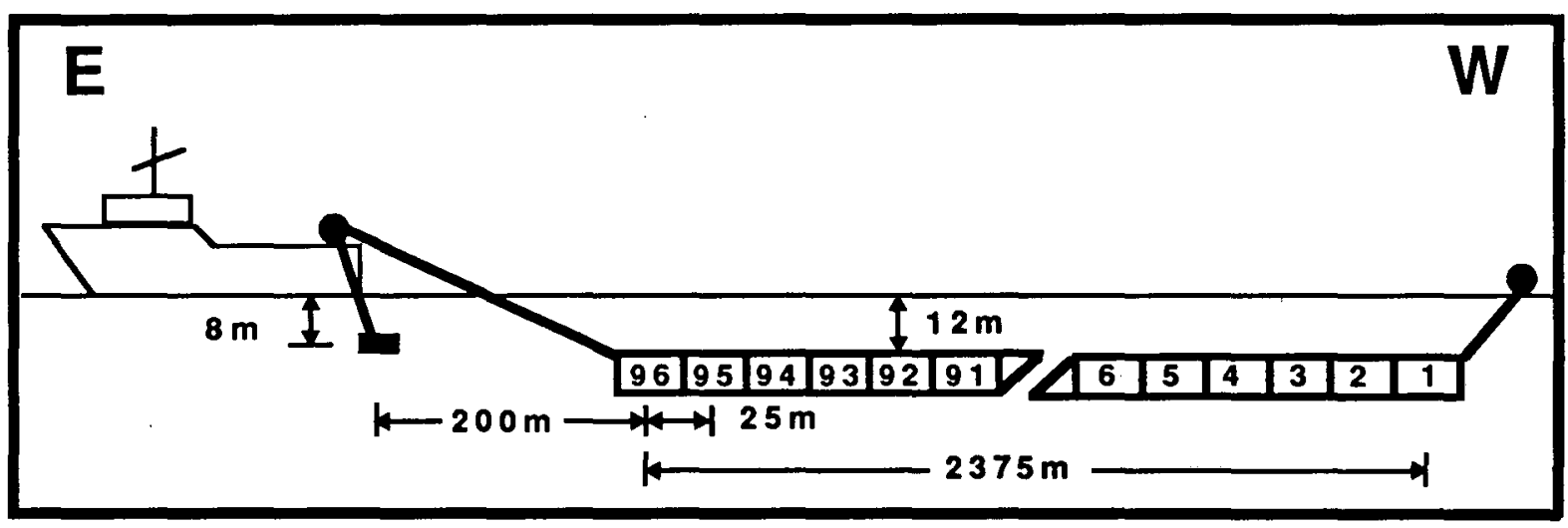

Figure 4. Streamer configuration for the data generation. 


\section{Data generation}

For the data generation we used a modeling package which performs the simulation of a whole seismic line across a geologic basin by computing successively the different shot records.

More specifically we used a $2 \mathrm{D}$ acoustic wave propagation modeler. This modeler uses a second order (both in space and time) explicit finitedifference scheme. Third-order absorbing boundary conditions (Chalindar 1988) are used to reduce the unwanted edge effects.

For such a scheme and for the considered seismic frequencies and velocities a grid size of 4 meters turned out to be an acceptable trade-off between numerical dispersion (Alford 1974) and computing cost. After the data generation the data were time filtered with a trapezoid frequency filter $(0,10,35,55 \mathrm{~Hz})$ to partly remove the numerical dispersion. However, even with this filtering and a small grid size some numerical dispersion is likely to occur for long-range lowvelocity propagation. Using a 4th-order scheme would have allowed a larger grid size and consequently cheaper computations but the complexity of the reflector geometries would have created grid diffractions if a coarser grid had been used. A subset of the data is shown in figures 5 and 6 (shotgathers), figures 7,8 and 9 (common offset gathers) and figure 10 (CMP gathers). From these figures the complexity of the data is evident.

\section{Data distribution}

Initially, the participants were given a tape with
- velocity, density and lithologic logs for depths between 0 and 3000 meters at horizontal positions 1504 and $9004 \mathrm{~m}$.

- the seismic data set, consisting of 240 shots, each with 96 traces.

- the geological description as given in the section "geological model description".

After the discovery that 5 shots had been slightly mispositioned, a corrected tape was sent out. This tape also included an additional well (at position $2700 \mathrm{~m}$ ) and a VSP recorded in this well.

Two weeks before the workshop, it was discovered that errors had been made in the geological description: the numbering of the lithologic logs of wells 1504 and 9004 had been inversed, and the words "east" and "west" used in the geological description had also been inversed."

The inversion of the well log numbering did not pose many problems, as the corresponding density and velocity profiles were correctly numbered, however the inversion in the geological description led to considerable confusion.

\section{Acknowledgements}

We thank Messrs Fail, Grau and Montadert for the support and advice they gave us during the project of generating the data. We also thank all colleagues of the IFP who have advised us during the model generation.

\footnotetext{
* This illustrates the well known difficulty of coordination between different geoscientists ...
} 


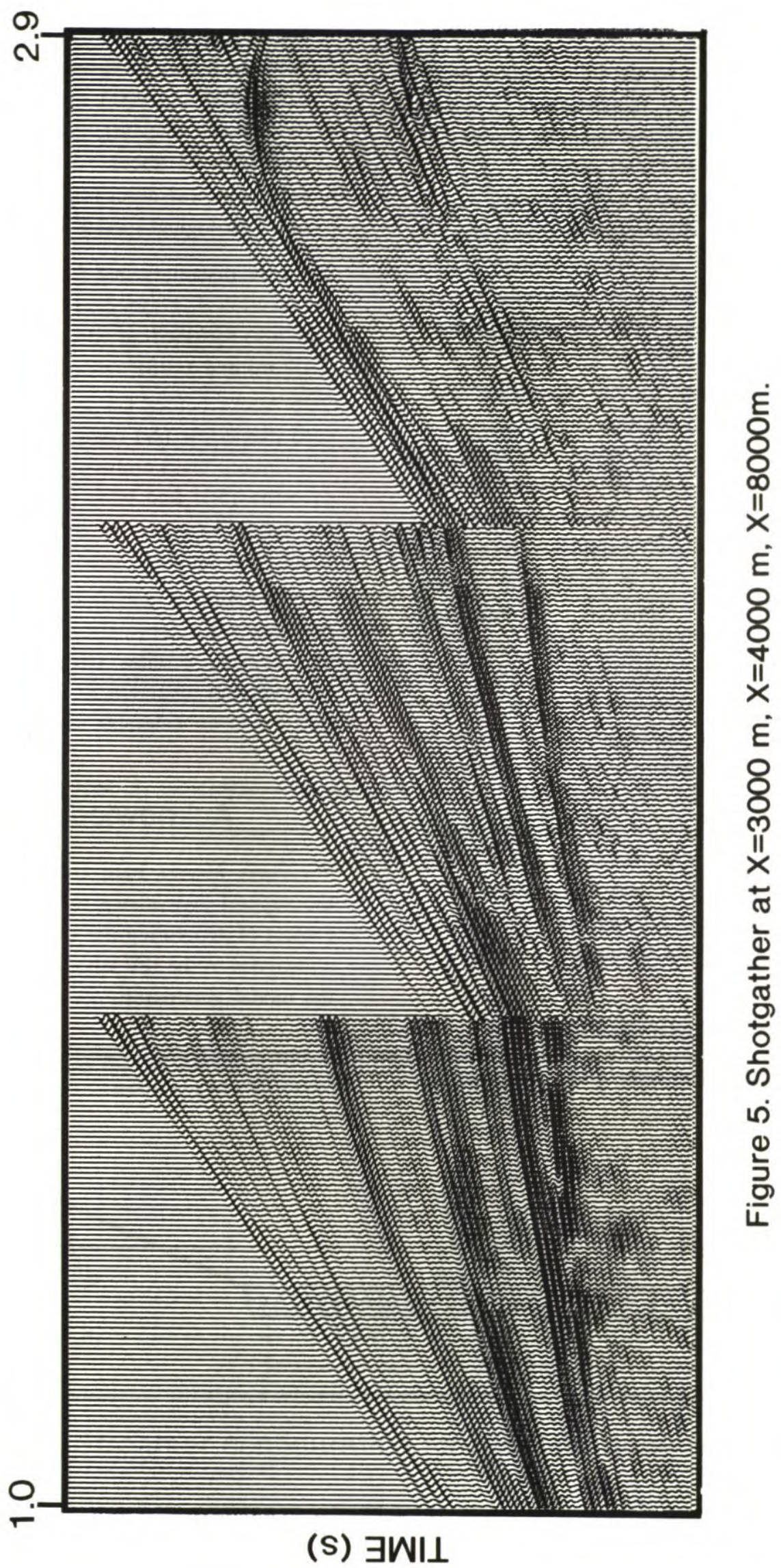




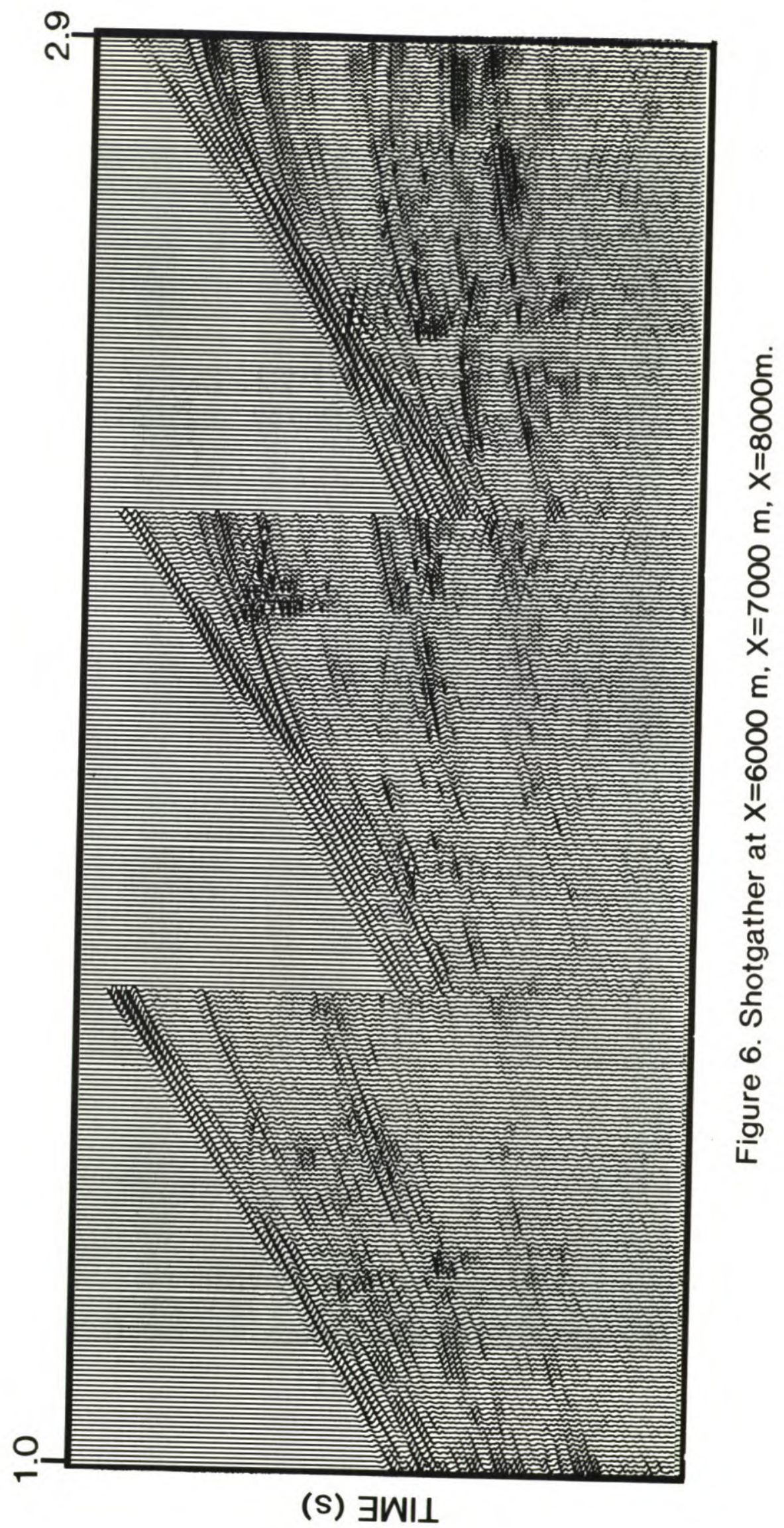




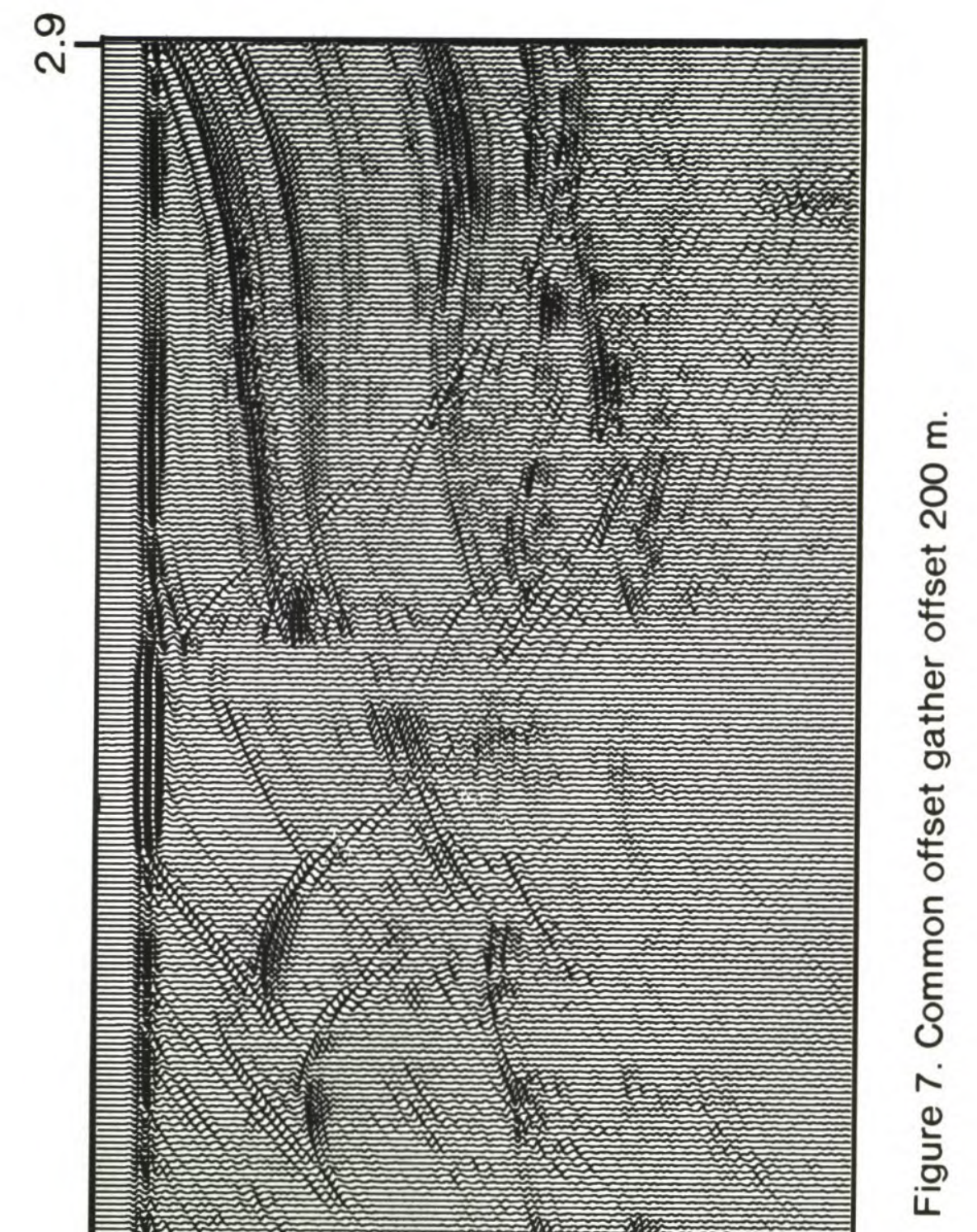




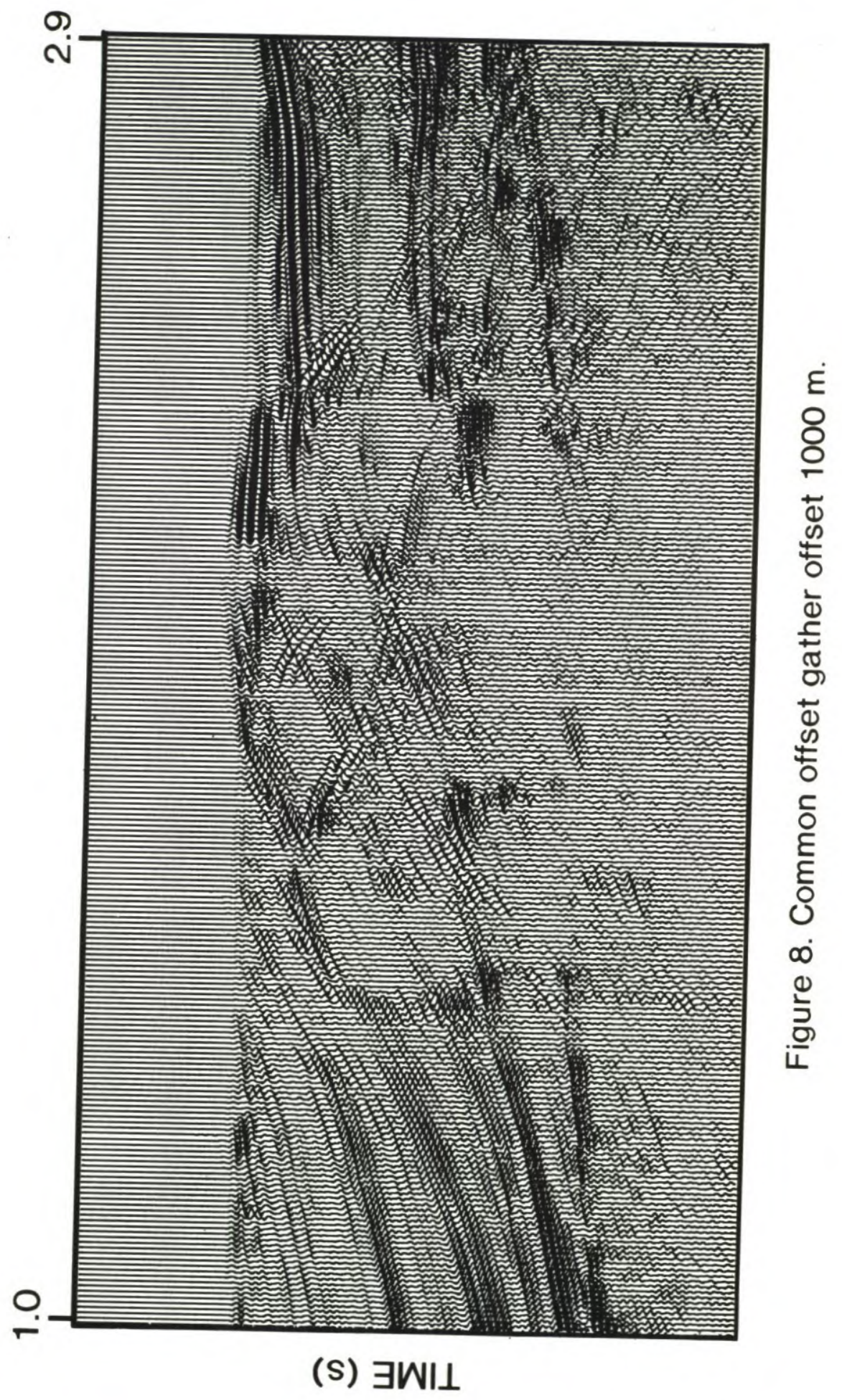




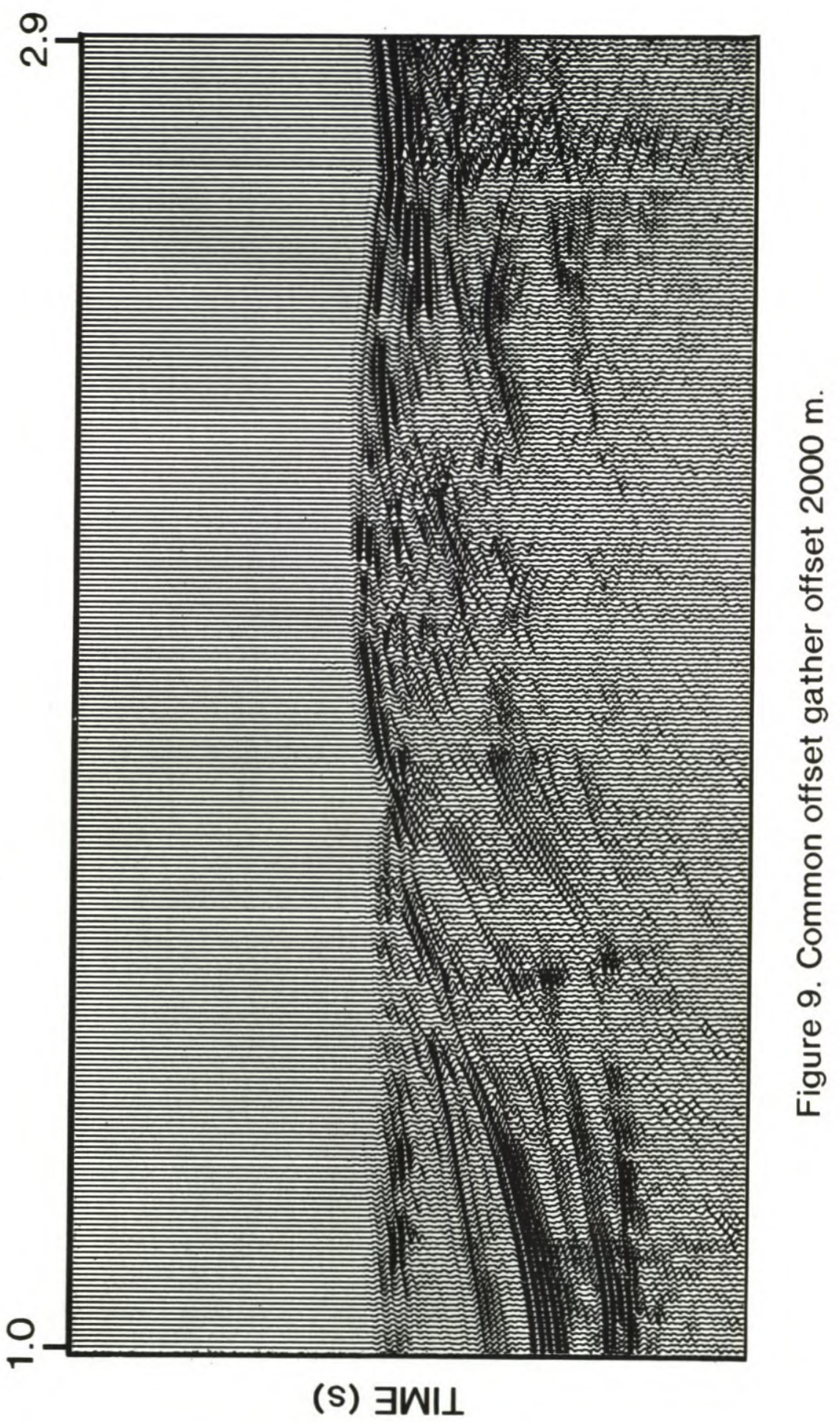




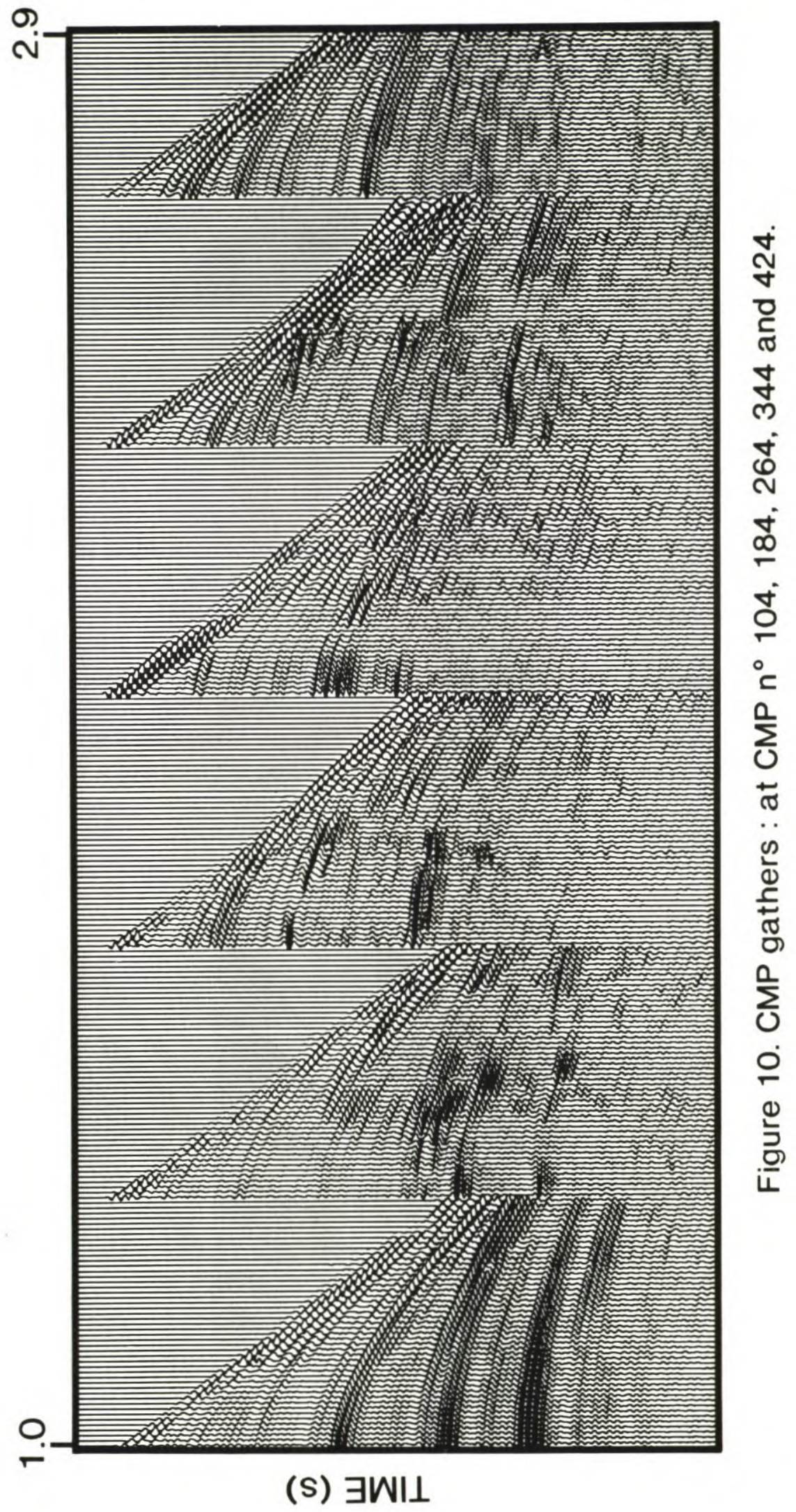




\section{References}

Alford, R. M., Kelly, K. R., and Boore, D. M., 1974, Accuracy of finite difference modeling of the acoustic wave equation, Geophysics, 39, 834-842.

Chalindar, B., 1988, Conditions aux limites absorbantes appliquees ad des problemes hyperboliques intervenant en sismique, $\mathrm{PhD}$ thesis, Universite de Saint Etienne.

Verrier, G., and Branco, F. C., 1972, La fosse tertiaire et le gisement de Quenguela-Nord, Revue de l'Institut Francais du Petrole, 27(1), 51-72. 